Review

\title{
A Review of the Positive Electrode Additives in Lead-Acid Batteries
}

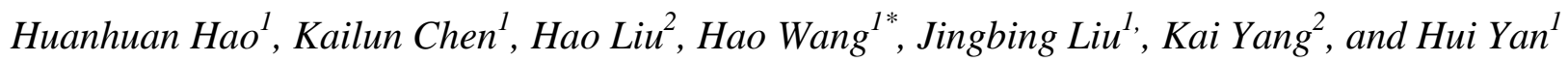 \\ ${ }^{1}$ The College of Materials Science and Engineering, Beijing University of Technology, Beijing \\ 100124, China. \\ ${ }^{2}$ State Key Laboratory of Operation and Control of Renewable Energy \& Storage Systems, China \\ Electric Power Research Institute, Beijing 100192, China. \\ *E-mail: haowang@bjut.edu.cn
}

doi: $10.20964 / 2018.03 .70$

Received: 6 December 2017 / Accepted: 14 January 2018 / Published: 5 February 2018

Lead acid battery occupies a very important position in the global battery market for its high security and excellent cost-effective. It is widely used in various energy storage systems, such as electric vehicles, hybrid electric vehicles, uninterruptible power supply and grid-scale energy storage system of electricity generated by renewable energy. Lead acid battery which operates under high rate partial state of charge will lead to the sulfation of negative electrode. Lead carbon battery, prepared by adding carbon material to the negative electrode of lead acid battery, inhibits the sulfation problem of the negative electrode effectively, which makes the problem of positive electrode become more prominent. As a result, more and more researchers are working on ways to improve the performance of the positive electrode, such as adding additives to positive active material. In this paper, the positive additives are divided into conductive additive, porous additive and nucleating additive from two aspects: the chemical properties of the additives and the effect on the performance of the lead-acid battery. The effect and mechanism of different additives on the structure and properties of positive electrode are discussed.

Keywords: Lead-acid battery, positive electrode, conductive additive, porous additive, nucleating additive

\section{FULL TEXT}

(C) 2018 The Authors. Published by ESG (www.electrochemsci.org). This article is an open access article distributed under the terms and conditions of the Creative Commons Attribution license (http://creativecommons.org/licenses/by/4.0/). 